\title{
A 35-fold enhancement in photocurrent generation of Synechocystis sp. PCC 6803 by outer membrane deprivation
}

\section{Shoko Kusama}

Graduate School of Engineering Science, Osaka University

\section{Seiji Kojima}

Panasonic Corporation

\section{Ken Kimura}

Osaka University

\section{Ginga Shimakawa}

Kobe University

\section{Chikahiro Miyake}

Kobe University

\section{Kenya Tanaka}

Osaka University

\section{Yasuaki Okumura}

Panasonic Corporation

Shuji Nakanishi ( $\nabla$ nakanishi@chem.es.osaka-u.ac.jp )

Osaka University

\section{Article}

Keywords: Biophotovoltaics, Synechocystis sp. PCC 6803, extracellular electron transfer

Posted Date: January 22nd, 2021

DOI: https://doi.org/10.21203/rs.3.rs-144761/v1

License: (c) (1) This work is licensed under a Creative Commons Attribution 4.0 International License. Read Full License

Version of Record: A version of this preprint was published at Nature Communications on June 2nd, 2022. See the published version at https://doi.org/10.1038/s41467-022-30764-z. 


\section{Abstract}

Biophotovoltaics (BPV) is an emerging technology developed to utilize reducing equivalents produced by photosynthetic organisms. It generates electrical power by exploiting a phenomenon called extracellular electron transfer (EET), where reducing equivalents are transferred extracellularly to exogenous electron acceptors. Although cyanobacteria have been extensively studied in BPV because of their high photosynthetic activity and ease of handling, their extremely low EET activity remains a limitation. In this study, we achieved a 35-fold enhancement in photocurrent generation of the cyanobacterium Synechocystis sp. PCC 6803 by deprivation of the outer membrane, where electrons are suggested to stem from NADPH; this, along with a significantly higher rate of exogenous ferricyanide reduction, verified that low permeability of the outer membrane contributues to low cyanobacterial EET activity. Moreover, outer membrane deprivation enhanced extracellular derivation of reducing equivalents serving as respiratory substrates for other heterotrophic bacteria, making it promising and useful for effective derivation of reducing equivalents.

\section{Introduction}

Recently, various technologies have been developed to utilize reducing equivalents produced by oxygenic photosynthesis, which absorbs light and oxidizes water to produce high energy electrons. Emerging among them is biophotovoltaics (BPV), in which the reducing equivalents are transferred extracellularly to electrodes or to other bacteria, a phenomenon called extracellular electron transfer (EET), eventually generating electrical power ${ }^{1-4}$. Cyanobacteria, which are gram-negative bacteria capable of performing oxygenic photosynthesis, have been extensively studied in the field of BPV research ${ }^{1-3}$. This is because cyanobacteria have higher photosynthetic activity than terrestrial plants, much like eukaryotic algae ${ }^{5-7}$. Moreover, they are easy to culture, amenable to genetic manipulation ${ }^{8}$, grow fast, and possess a simple cell structure compared with eukaryotes. Many studies on the mechanism of EET have been conducted using cyanobacteria ${ }^{9-15}$, and so far, direct EET via conductive nanowires ${ }^{16}$ and indirect, mediated EET by endogenous mediators ${ }^{14,15,17}$ have been put forward as possible EET pathways; some suggest that the latter is more likely than the former to occur in the case of cyanobacteria ${ }^{2,18}$.

Although much progress has been made in the field of BPV in the past decade, the extremely low EET activity of cyanobacteria remains a limitation. The EET activity of cyanobacteria, both in the dark and under illumination, is extremely low compared with that of mineral-reducing, electricity-generating bacteria, e.g. the genera Shewanella and Geobacter ${ }^{2}$, which are capable of utilizing diverse electron acceptors including an anode ${ }^{19}$. As previously pointed out, the main reason for the low EET activity of cyanobacteria is their autotrophy, in which EET could be totally useless and wasteful because electrons originating from phosynthesis should be fully utilized to provide enough reducing equivalents and energy to fix carbon ${ }^{1}$. Here, we hypothesize an additional reason for the extremely low EET activity of cyanobacteria: the low permeability of the outer membrane. The outer membrane of cyanobacteria exhibits more than 20-fold lower permeability to organic substrates than that of Escherichia coli, the 
model gram-negative bacteria ${ }^{20}$. This low permeability is thought to reflect its autotrophic life style $\mathrm{e}^{20,21}$, which does not necessarily rely on uptake of extracellular nutrients, although various transport systems do exist and function in cyanobacteria $22-24$.

In this study, using an outer membrane-deprived Synechocystis sp. PCC 6803 (hereafter Synechocystis) mutant, slr0688i 25 , we achieved a significant enhancement in cyanobacterial EET activity. EET activity was evaluated as extensively as possible in terms of photocurrent generation, ferricyanide reduction, and electron donation capacity as respiratory substrates (Fig. 1). This study clearly verified our hypothesis that the low permeability of the outer membrane contributes to the extremely low EET activity of cyanobacteria.

\section{Results}

\section{Mediated EET was enhanced by outer membrane deprivation.}

First, to compare the EET activity of the outer membrane-deprived mutant, slr0688i ${ }^{25}$, with that of the wild type, dCas9, the photocurrent from both strains was measured. Slr0688i and dCas9 resuspended in their respective supernatants were injected by gravity onto flat indium tin oxide (ITO) electrodes to which + $0.25 \mathrm{~V}$ vs. $\mathrm{Ag} / \mathrm{AgCl}$ was applied, and the current generated under illumination was recorded. Slr0688i generated 35 times as much photocurrent as dCas9 on average (Fig. 2(a)), and approx. 100 times as much photocurrent $\left(0.4 \mu \mathrm{A} / \mathrm{cm}^{2}\right)$ as dCas $9\left(0.007 \mu \mathrm{A} / \mathrm{cm}^{2}\right)$ at maximum (Fig. 2(b)) with flat ITO electrodes. To confirm that the observed enhancement in photocurrent generation of slr0688i did not stem from increased photosynthetic activity, the oxygen evolving activities of slr0688i and dCas 9 were measured and compared. Under illumination with high light $\left(750 \mu \mathrm{mol}\right.$ photons $\left.\mathrm{m}^{-2} \mathrm{~s}^{-1}\right)$, neither photosynthetic nor respiratory activity was significantly different between them on a chlorophyll basis (Supplementary Fig. 1); moreover, under illumination with moderate light $\left(120 \mu \mathrm{mol}\right.$ photons $\left.\mathrm{m}^{-2} \mathrm{~s}^{-1}\right)$, the photosynthetic activity of slr0688i was slightly lower than dCas9 (Supplementary Fig. 1). These results indicated that the enhanced photocurrent generation of slr0688i is not attributable to increased photosynthetic activity but to its outer membrane deprivation.

Next, to examine the necessity of supernatants in photocurrent generation, the supernatant of slr0688i was substituted with that of dCas9 or fresh BG11, and the photocurrent was measured. Photocurrent generation from slr0688i was not affected by substitution with the supernatant of dCas9 (Fig. 2(c); orange solid versus dotted line) but was abolished by substitution with fresh BG11 (Fig. 2(c); orange versus red solid line). In contrast, dCas 9 did not generate a photocurrent with the supernatant of either slr0688i ((Fig. 2(c); black dotted line) or dCas9 ((Fig. 2(c); black solid line) under our experimental conditions. These results demonstrated that redox-active, secreted compounds included in the supernatants of slr0688i and dCas 9 serve as electron mediators in photocurrent generation. Some anodic peaks were observable in cyclic voltammograms taken from slr0688i resuspended in its supernatant (Supplementary Fig. 2), which are possibily attributable to redox-active compounds secreted in the supernatant. These observations are consistent with recent suggestions that cyanobacterial secreted 
compounds serve as endogenous electron mediators in photocurrent generation from wild-type cells $^{2,14,15}$. In addition, a photocurrent was observed with the supernatant of slr0688i containing compounds with $\mathrm{MW}<3,000$ but not with $\mathrm{MW}>3,000$ (Supplementary Fig. 3 ), which is consistent with the widely accepted prediction that small molecular compounds such as quinones and flavines might be responsible for photocurrent generation ${ }^{2}$. Taken together, these results indicated that outer membrane deprivation facilitates mediated EET, which requires secreted redox-active compounds regardless of deprivation of the outer membrane.

\section{Electrons are suggested to stem from NADPH.}

To identify the main site where the reducing equivalents involved in photocurrent generation are derived from slr0688i, several photosynthesis inhibitors were applied to Synechocystis cells and their effects on current generation were examined. The effects of the inhibitors were evaluated by total coulombs produced from both the photosynthetic and respiratory chains of the cells during a 10-min illumination, because the photosynthetic chain shares some components with the respiratory chain in Synechocystis cells $^{26-28}$. slr0688i was treated with $p$-chloromercuribenzoate (pCMB), 3-(3,4-dichlorophenyl)-1,1dimethylurea (DCMU), or potassium cyanide $(\mathrm{KCN})$ prior to injection into the chambers, and the photocurrent was recorded at $+0.25 \mathrm{~V}$ vs. $\mathrm{Ag} / \mathrm{AgCl}$.

Treatment with pCMB led to a 30 -fold increase in the total coulombs (\% vs controls) (Fig. 3(a)), most of which were produced light-dependently (Supplementary Fig. 4(a)). When slr0688i was treated with pCMB, oxygen evolution under illumination was inhibited (Supplementary Fig. 5(a)). Then, the effect of pCMB on changes in NADPH fluorescence was examined with a pulse modulation fluorometer (Dual-PAM-100); pCMB-treated slr0688i cells generated NADPH (approximate half-time, $0.21 \mathrm{sec}$ ) as fast as cells incubated only with the solvent DMSO (approximate half-time, $0.17 \mathrm{sec}$ ), under illumination with actinic light (Fig. 4). This indicated that pCMB inhibits photosynthesis (Supplementary Fig. 5(a)), but its target site is not located before generation of NADPH. When treated with DCMU, which unequivocally inhibits electron transfer from $Q_{A}$ to $Q_{B}$ in $P S \|^{29,30}$, the total coulombs produced by slr0688i dropped to $52 \%$ of that of the control (Fig. 3(a)), where only residual current was generated light-dependently (Supplementary Fig. 4(b)). These results indicated that electrons are derived from somewhere after $Q_{A}$. When treated with $\mathrm{KCN}$, the total coulombs produced by slr0688i under illumination was only $14 \%$ of that of the control (Fig. 3(a)), and no photocurrent was generated (Supplementary Fig. 4(c)). KCN inhibits all the respiratory terminal oxidases ${ }^{31-33}$ as well as plastocyanin ${ }^{34-36}$; indeed, $\mathrm{KCN}$-treated slr0688i cells did not exhibit oxygen evolution under illumination (Supplementary Fig. 5(b)).

Consistent with previous reports $2,11,12$, the results described above suggested that the electrons involved in photocurrent generation stem from NADPH (Fig. 3(b)). This was further supported by an additional experiment using phenylmercuric acetate (PMA), an inhibitor of ferredoxin and/or $\mathrm{FNR}^{37,38}$; treatment with PMA abolished the photocurrent of slr0688i (Supplementary Fig. 6). When steady-state NADP $(H)$ contents and the $\mathrm{NADP}^{+} / \mathrm{NADPH}$ ratio were quantified, there were no significant differences between 
slr0688i and dCas9 (Supplementary Fig. 7); this indicated that the enhanced photocurrent generation from slr0688i is not due to an increase in the amount of reducing equivalents but to outer membrane deprivation.

\section{Ferricyanide-mediated EET was enhanced by outer membrane deprivation.}

Because the catalytic activity of a flat ITO electrode is very poor, the EET activity of Synechocystis cells could not be fully evaluated by photocurrent measurements. Therefore, the rate of EET to a hydrophilic electron acceptor, ferricyanide, was measured next. Cell suspensions of slr0688i and dCas 9 were mixed with $1 \mathrm{mM}$ potassium ferricyanide, and changes in the ferricyanide concentration under illumination or in the dark were monitored spectroscopically. Under illumination, slr0688i reduced the extracellularly added ferricyanide at a rate of $2.3 \mu \mathrm{M} / \mathrm{OD}$ min, whereas dCas 9 exhibited no reduction of ferricyanide in the tested time range (Fig. 5(a)(c)). In the dark, slr0688i reduced ferricyanide at a lower rate (0.8 $\mu \mathrm{M} / \mathrm{OD} \mathrm{min})$ than under illumination but still at a significantly higher rate than dCas9 in the same conditions (Fig. 5(b) (d)). Substitution of the supernatant with fresh BG11 did not affect the rate of ferricyanide reduction either under illumination or in the dark (Fig. 5), indicating that ferricyanide-mediated EET, which could not be detected by the photocurrent measurements (Fig. 2(c)), was detected by this assay. It is widely accepted that, with its hydrophilicity, ferricyanide freely passes the outer membrane and accepts

electrons from Synechocystis cells ${ }^{39}$ via some transmembrane protein at the cytoplasmic membrane ${ }^{11,12}$; however, these results indicated that the outer membrane does serve as a barrier to ferricyanide access to the cytoplasmic membrane. Together with the results of the photocurrent measurements, these results clearly showed that deprivation of the outer membrane leads to a significant increase of both mediated and ferricyanide-mediated EET.

\section{Extracellular derivation of reducing equivalents was enhanced by outer membrane deprivation.}

In an attempt to detect and evaluate EET activity more extensively, we examined the electron donation capacity of extracellularly derived reducing equivalents as respiratory substrates for other bacteria. These extracellular reducing equivalents, which are considered energy carriers, i.e. electron donors, in the BPV system ${ }^{4}$, cannot be detected and evaluated by photocurrent measurements or a ferricyanide reduction assay. Therefore, Bacillus cereus (hereafter Bacillus), which is a gram-positive model organism, was chosen as a recipient of these reducing equivalents. Changes in its membrane potential were monitored as an indicator of electron donation to the respiratory chain because membrane potential generation should be accompanied by extrusion of protons due to electron transfer through the respiratory chain.

Supernatants of slr0688i and dCas9 were added to carbonyl cyanide $m$-chlorophenylhydrazone (CCCP)treated Bacillus cells and the generation of membrane potential in the Bacillus cells was monitored using the voltage-sensitive dye 3,3'-dipropylthiadicarbocyanine iodide $\left(\operatorname{DiSC}_{3}(5)\right)$. To generate enough membrane potential to calculate the rates of formation, the supernatants were concentrated to $5 \times$ by ultrafiltration and the obtained retentates (containing compounds with $M W>3,000$ ) were added to Bacillus cells. Generation of membrane potential was twice as fast with the supernatant of slr0688i as 
that of dCas9 (Fig. 6(a)), indicating that the slr0688i supernatant possessed higher electron donation capacity as respiratory substrates compared with dCas9. Experiments with membrane vesicles isolated from Bacillus subtilis indicated that the compounds included in the supernatant of slr0688i do not donate electrons directly to the respiratory chain of Bacillus cells as a mixture of PMS/ascorbate does (Supplementary Fig. 8); therefore, the observed generation of membrane potential is suggested to result from metabolization of compounds in the supernatant of slr0688i by Bacillus cells, which feeds electrons to their respiratory chain. Consistent with this, compounds with $\mathrm{MW}<3,000$ were capable of generating membrane potential more than five times as fast as compounds with MW >3,000 (Supplementary Fig. 9), reflecting that simpler, lower molecular weight compounds are metabolized more efficiently and thus donate electrons to the respiratory chain at a faster rate.

To quantify the electron donation capacity as respiratory substrates, the rate of membrane potential generation was measured and compared with those of glucose solutions of different concentrations; a $0.5 \times$ concentration of slr0688i supernatant was revealed to generate membrane potential as fast as $4 \mu \mathrm{M}$ glucose (Fig. 6(b)); that is, the electron donation capacity of slr0688i supernatant was equal to $8 \mu \mathrm{M}$ glucose.

\section{Discussion}

In this study, using an outer membrane-deprived Synechocystis sp. PCC 6803 (hereafter Synechocystis) mutant, slr0688i ${ }^{25}$, we achieved a 35 -fold enhancement in photocurrent generation and a significantly higher rate of exogenous ferricyanide reduction. These results clearly indicate that deprivation of the outer membrane enhances EET, i.e. extracellular derivation of reducing equivalents originating from photosynthesis, and verified our hypothesis that the low permeability of the outer membrane contributes to low cyanobacterial EET activity. This is the first report that as much as a 35 -fold increase in EET activity can be achieved by genetic engineering ${ }^{25}$, providing clues for further improvement and development of BPV systems.

This study revealed that deprivation of the outer membrane is one of the most promising technologies to improve the efficiency of BPV systems. Based on the data shown in Fig. 5 and the chlorophyll content of slr0688i $\left(5.6 \mu \mathrm{g} \mathrm{Chl}\left(\mathrm{mL} \mathrm{OD}_{730}\right)^{-1}\right)$, the rate of EET from slr0688i to ferricyanide is calculated to be $14.6 \mathrm{nmol}$ electrons $\mathrm{nmol} \mathrm{chl}{ }^{-1} \mathrm{~h}^{-1}$ under illumination. This is higher than the fastest rate reported with terminal oxidase mutants; $2.7 \mathrm{nmol}$ electrons $\mathrm{nmol} \mathrm{chl}{ }^{-1} \mathrm{~h}^{-1}$ in the Cyd/ARTO double mutant, which we calculated using the data reported in Table S2 in Bradley et al., 2013 ${ }^{12}$. What is more promising about slr0688i is that the photocurrent generation does not need special treatments other than simple application of planktonic cells by gravity onto a flat, unmodified ITO electrode. Therefore, further enhancement in photocurrent generation may be achievable by various methods that have already proven effective in other studies: optimization ${ }^{40}$ or modification of the electrodes ${ }^{14,41,42}$, formation of biofilms on electrodes ${ }^{14,43,44}$, deposition of concentrated biomass onto an electrode followed by dessication ${ }^{13}$, mild microfluidization of the cells ${ }^{15}$, utilization of aged cell cultures deficient in iron ${ }^{45}$, or 
digital printing of cells on paper ${ }^{46}$. Genetic engineering in addition to outer membrane deprivation would unequivocally be beneficial to further improvement, as already demonstrated in several studies ${ }^{12,47}$.

This study suggests that electrons originating from NADPH are involved in the enhanced photocurrent generation from the outer membrane-deprived mutant. This is consistent with previous studies suggesting that the electrons involved in photocurrent generation stem from PSI electron acceptors, i.e. ferredoxin and/or $\operatorname{NADP}(H)^{2,11,12}$. One of the strongest pieces of evidence of EET originating from NADPH is the observation that M55, a mutant lacking functional NDH complexes, exhibited a significant enhancement in EET to ferricyanide both in the dark and under illumination ${ }^{12}$, which should result from the overaccumulation of $\mathrm{NAD}(\mathrm{P}) \mathrm{H}$.

In the NADPH fluorescence measurements (Fig. 4), the decrease of fluorescence after switching off the actinic light was slower in PCMB-treated cells than in non-treated cells; the approximate half-time of the decrease was $1.38 \mathrm{~s}$ and $0.66 \mathrm{~s}$, respectively. This sugests that $\mathrm{PCMB}$-treated cells do not consume NADPH as fast as non-treated cells because some reaction(s) related to the Calvin cycle is inhibited by pCMB. This is consistent with its inhibitory effect on oxygen evolution (Supplementary Fig. 5(a)), because inhibition of the Calvin cycle leads to a halt of oxygen evolution as shown in, e.g., Table 1 in Takahashi and Murata, $2005^{48}$. In addition, a transient increase in fluorescence after switching off the light due to the pentose phosphate pathway was observed in non-treated cells, but not in pCMB-treated cells (Fig. 4); this further suggests that a Calvin cycle-related reaction(s) is somehow inhibited in pCMB-treated cells and thus organic compounds that are metabolized by the pentose phosphate pathway and yield NADPH are not generated. Previous studies suggested that the target sites of PCMB are iron-sulfur clusters of isolated ferredoxin ${ }^{49}$ as well as of $\mathrm{PSI}^{50}, \mathrm{NAD}(\mathrm{P}) \mathrm{H}$ dehydrogenase (NDH) 1 and 2 in algal thylakoid membranes ${ }^{51}$, or enzymes involved in the Calvin cycle in intact cyanobacterial cells ${ }^{52}$. A more precise idetification of the target sites of $\mathrm{pCMB}$ in vivo is now in progress.

Deprivation of the outer membrane is undoubtedly beneficial not only for the improvement of BPV systems but also for enhancing production of various chemicals ranging from biofuels to high-value compounds ${ }^{53-60}$. Supporting this is a previous study showing that slr0688i secretes enough nutrients to support the growth of heterotrophs ${ }^{25}$; moreover, this study also showed that the supernatant of slr0688i provides respiratory substrates to Bacillus cells as efficiently as $8 \mu \mathrm{M}$ glucose. Many beneficial aspects of the outer membrane-deprived mutant remain to be explored, and full utilization of its photosynthetic reaction is a promising way to achieve a clean and sustainable future.

\section{Materials And Methods}

\section{Bacterial strains and general growth conditions.}

The Synechocystis strains used in this study were slr0688i, whose outer membrane is deprived due to conditional repression of s/r0688 by the CRISPRi system regulated by both dCas 9 and sgRNA, and dCas9, a control strain (serving as the wild-type strain in this study) whose chromosomal DNA contains the same 
genetic construct as slr0688i without the sgRNA ${ }^{25}$. These strains were grown photoautotrophically at $30{ }^{\circ} \mathrm{C}, 100 \mu \mathrm{mol}$ photons $\mathrm{m}^{-2} \mathrm{~s}^{-1}$, with constant shaking at $140 \mathrm{rpm}$ in BG11 medium consisting of the following ingredients (per $\mathrm{L}$ ): $2 \mathrm{~mL}$ of Solution I $\left(0.5 \mathrm{~g} / \mathrm{L} \mathrm{Na}{ }_{2} E D T A \cdot 2 \mathrm{H}_{2} \mathrm{O}, 3 \mathrm{~g} / \mathrm{L}\right.$ ammonium iron (III) citrate, $3 \mathrm{~g} / \mathrm{L}$ citric acid), $25 \mathrm{~mL}$ of Solution II-a (60 g/L NaNO $\left.3,3 \mathrm{~g} / \mathrm{L} \mathrm{MgSO}_{4}\right), 25 \mathrm{~mL}$ of Solution II-b (1.56 g/L K $\left.{ }_{2} \mathrm{HPO}_{4}\right), 2 \mathrm{~mL}$ of Solution III (14.3 g/L CaCl$), 1 \mathrm{~mL}$ of A6 Solution $\left(2.86 \mathrm{~g} / \mathrm{L} \mathrm{H}_{3} \mathrm{BO}_{3}, 1.81 \mathrm{~g} / \mathrm{L}\right.$ $\mathrm{MnCl}_{2} \cdot 4 \mathrm{H}_{2} \mathrm{O}, 0.22 \mathrm{~g} / \mathrm{L} \mathrm{ZnSO}{ }_{4} \cdot 7 \mathrm{H}_{2} \mathrm{O}, 0.08 \mathrm{~g} / \mathrm{L} \mathrm{CuSO}_{4} \cdot 5 \mathrm{H}_{2} \mathrm{O}, 0.021 \mathrm{~g} / \mathrm{L} \mathrm{Na}_{2} \mathrm{MoO}_{4} \cdot \mathrm{H}_{2} \mathrm{O}, 0.0494 \mathrm{~g} / \mathrm{L}$ $\mathrm{Co}\left(\mathrm{NO}_{3}\right)_{2} \cdot 6 \mathrm{H}_{2} \mathrm{O}$, 1 droplet of $\left.\mathrm{H}_{2} \mathrm{SO}_{4}\right)$, and $20 \mathrm{~mL}$ of $1 \mathrm{M} \mathrm{TES}-\mathrm{KOH}(\mathrm{pH} 7.5)$. Deprivation of the outer membrane of slr0688i was induced by treating precultured cells dilluted to $\mathrm{OD}_{730}=0.1$ with $1 \mu \mathrm{g} / \mathrm{mL}$ anhydrotetracycline dissolved in DMSO, as described in Kojima and Okumura, 202025. Synechocystis cells at log phase were used in all the following experiments.

Electrochemical measurements. The electrochemical setup was composed of a cylindrical glass chamber ( $20 \times 30 \mathrm{~mm}$; geometrical surface area, $3.14 \mathrm{~cm}^{2}$ ), an ITO-coated glass (GEOMATEC) as a working electrode placed at the bottom of the chamber, a platinum wire as a counter electrode, and a $\mathrm{Ag} / \mathrm{AgCl}$ reference electrode (HOKUTO DENKO). All electrochemical measurements were conducted at $30^{\circ} \mathrm{C}$ with either a potentiostat/galvanostat HA-1510 (HOKUTO DENKO) or electrochemical analyzer Model 760C (ALS).

Common procedures for electrochemical measurements performed in the current study were as follows: Synechocystis cell suspensions of $4 \mathrm{~mL}$ were separated into sedimented cells and supernatant by centrifugation at 2,500 $\times g$ for $10 \mathrm{~min}$, and the supernatant was first injected into the electrochemical chamber. The sedimented cells were then resuspended with the rest of the supernatant, drawn up into a syringe, injected by gravity onto the ITO glass at the bottom of the chamber, and incubated to settle the cells down.

To avoid detection of a pseudo-photocurrent, which is explained in detail below, the $\mathrm{pH}$ of Synechocystis cell suspensions was always confirmed and adjusted when necessary prior to electrochemical measurements. The $\mathrm{pH}$ of the suspension preferably should be below approximately 8.0 , and should never be above 8.5. Otherwise, the buffering capacity of TES ( $\mathrm{pH} 6.8-8.2)$ is outcompeted by drastic changes (increases) in the $\mathrm{pH}$ of the medium due to photosynthesis ${ }^{61-63}$, resulting in detection of a pseudo-photocurrent of the following reaction:

$\mathrm{Mn}^{2+}+2 \mathrm{H}_{2} \mathrm{O} \rightleftharpoons \mathrm{Mn}^{3+}(\mathrm{OOH})+3 \mathrm{H}^{+}+\mathrm{e}^{-}$,

where $\mathrm{Mn}^{2+}$ comes from $\mathrm{MnSO}_{4}$, a component of the BG11 medium. Some examples of detected pseudophotocurrents of manganese are shown and described in detail in Supplementary Fig. 10. Therefore, before electrochemical measurements, the $\mathrm{pH}$ of cell suspensions was always confirmed to be below approximately 8.0 , and when necessary, fresh $\mathrm{BG} 11$ or $\mathrm{HCl}$ was added not only to adjust the optical density, but also the $\mathrm{pH}$ of cell suspensions below approx. 8.0. In chronoamperometry, the applied voltage 
was fixed to $+0.25 \mathrm{~V}$ vs. $\mathrm{Ag} / \mathrm{AgCl}$, at which sufficient current generation occurred (Supplementary Fig. 11) and a psedo-photocurrent was never detected under an appropriate pH (Supplementary Fig. 10).

When the supernatant needed to be replaced, it was removed after centrifugation and substituted with the supernatant of interest, which was prepared by filtration with an Ultrafree-MC-GV, $0.22 \mu \mathrm{m}$ (Millipore), or with fresh BG11.

Size-fractionated supernatants were prepared as follows: the supernatant was first filtrated from a cell suspension of slr0688i with a Millex-GV Syringe Filter Unit, $0.22 \mu \mathrm{m}$ (Millipore) and freeze-dried with a freeze dryer (TOKYO RIKAKIKAI). The obtained powder was suspended with water to yield a 10x concentrated supernatant and size fractionated by ultrafiltration with Amicon Ultra Centrifugal Filters (Millipore) to yield a supernatant containing compounds with $M W>50,000,>30,000,>3,000$ and $<3,000$. Each fraction was then diluted to $0.1 \times$ concentration with fresh BG11, and mixed with slr0688i cells to measure photocurrent generation.

For experiments using $\mathrm{pCMB}, \mathrm{DCMU}$, and $\mathrm{KCN}$, cell suspensions adjusted to $\mathrm{OD}_{730}=1.5$ and $\mathrm{pH} 7.6$ by adding fresh BG11 were incubated with $100 \mu \mathrm{M} \mathrm{pCMB}, 10 \mu \mathrm{M} \mathrm{DCMU}$, or $5 \mathrm{mM} \mathrm{KCN}$ for $1.5 \mathrm{~h}$ in the dark on ITO in the electrochemical chambers prior to electrochemical measurements. Additional experiments using $50 \mu \mathrm{M}$ PMA were performed with cell suspensions whose chlorophyll concentration was $12 \mu \mathrm{g}$ $\mathrm{Chl} / \mathrm{mL}$ and $\mathrm{pH}$ was adjusted to 7.6 by adding $\mathrm{HCl}$.

Ferricyanide assay. The rate of ferricyanide reduction was measured using $2.1 \mathrm{~mL}$ of Synechocystis cell suspensions adjusted to $\mathrm{OD}_{730}=1.0$. Then, $1 \mathrm{mM}$ potassium ferricyanide was added to the cell suspensions and they were incubated at $30^{\circ} \mathrm{C}$ with constant shaking at $140 \mathrm{rpm}$ either under illumination $\left(50 \mu \mathrm{mol}\right.$ photons $\mathrm{m}^{-2} \mathrm{~s}^{-1}$ ) or in the dark. Changes in the concentration of ferricyanide (extinction coefficient, $1.052 \mathrm{mM} \mathrm{cm}^{-1}$ ) were monitored up to approx. $140 \mathrm{~min}$ by measuring absorbance at $420 \mathrm{~nm}$ with a UV/VIS spectrophotometer UV-1850 (SHIMADZU).

Steady-state oxygen evolution and uptake measurements. The photosynthetic activity of Synechocystis cells was evaluated with a Clark-type electrode (Hansatech) at $25^{\circ} \mathrm{C}$. To measure steady state photosynthetic activity, $2 \mathrm{~mL}$ of cell suspension $(12 \mu \mathrm{g} \mathrm{Chl} / \mathrm{mL})$ containing $5 \mathrm{mM} \mathrm{NaHCO}_{3}$ was illuminated with a CoolLED pE-100 LED at PPFD of $750 \mu$ mol photons $\mathrm{m}^{-2} \mathrm{~s}^{-1}$. Dark respiration was evaluated from the oxygen consumption rate before switching on the light, and photosynthetic activity was calculated by adding the rate of dark respiration to that of oxygen evolution under illumination.

The same oxygen electrode setup was used to analyze the effects of KCN and pCMB on photosynthetic activity. In the case of KCN, Synechocystis cells were collected and resuspended with fresh BG11 to a final concentration of $12 \mu \mathrm{g} \mathrm{Chl} / \mathrm{mL}$, and mixed with $5 \mathrm{mM} \mathrm{NaHCO}_{3}$ and $5 \mathrm{mM} \mathrm{KCN}$, immediately after which oxygen evolving activity was measured. In the case of PCMB, Synechocystis cells collected and resuspended with fresh BG11 $(24 \mu \mathrm{g} \mathrm{Chl} / \mathrm{mL})$ were incubated either with $100 \mu \mathrm{M}$ pCMB or with its solvent 
DMSO for $1.5 \mathrm{~h}$ in the dark. The cell suspensions were then mixed with $5 \mathrm{mM} \mathrm{NaHCO}_{3}$ and diluted to $12 \mu \mathrm{g} \mathrm{Chl} / \mathrm{mL}$ with fresh BG11, followed by immediate measurement with an oxygen electrode.

\section{NADPH fluorescence.}

NADPH fluorescence was measured with a DUAL-PAM-100 (Walz) instrument as described previously ${ }^{64,65}$. Slr0688i cells collected and resuspended with fresh BG11 $(24 \mu \mathrm{g} \mathrm{Chl} / \mathrm{mL})$ were incubated either with $100 \mu \mathrm{M} \mathrm{pCMB}$ or with its solvent DMSO for at least $1.5 \mathrm{~h}$ in the dark. The cell suspensions were then injected and diluted to $2.4 \mu \mathrm{g} \mathrm{Chl} / \mathrm{mL}$ in a $1 \times 1 \mathrm{~cm}$ cuvette installed in the DUAL-PAM. The measuring light of $365 \mathrm{~nm}$ was set at an intensity of 10 on the DUAL-PAM software, and the measuring frequency was programmed to increase from 500 to $5000 \mathrm{~Hz}$ during illumination with actinic light of $635 \mathrm{~nm}$ at $785 \mu \mathrm{mol}$ photons $\mathrm{m}^{-2} \mathrm{~s}^{-1}$.

\section{$\mathrm{NADP}^{+} / \mathrm{NADPH}$ quantification assay.}

The amount of NADP ${ }^{+} / \mathrm{NADPH}$ in Synechocystis cells was quantified using an NADP ${ }^{+} / \mathrm{NADPH}$ Assay KitWST (DOJINDO), following the manufacturer's manual.

Fluorometric measurement of membrane potential of Bacillus cells. Bacillus cereus (hereafter Bacillus) cells were cultured at $30^{\circ} \mathrm{C}$ with constant shaking at $140 \mathrm{rpm}$ in Luria-Bertani (LB) medium. An overnight preculture was diluted 100-fold in fresh LB medium and grown for another $5 \mathrm{~h}$ before analysis. Bacillus cells were then collected by centrifugation at $10,000 \times g$ for 4 min and resuspended in fresh BG11 medium, whose $\mathrm{OD}_{600}$ was adjusted to approx. 0.3. CCCP dissolved in DMSO was added to a final concentration of $30 \mu \mathrm{M}$, and the cell suspension was incubated for $30 \mathrm{~min}$ at $30^{\circ} \mathrm{C}$ with constant shaking at $140 \mathrm{rpm}$. The cells were then collected and washed once with BG11 to remove the CCCP, followed by final resuspension with $B G 11$, in which the cells were allowed to rest for about 40 min (here, the $O_{600}$ of the cell suspention was supposed to be approx. 0.6). A voltage-sensitive dye, $\operatorname{DiSC}_{3}(5)$, was used to monitor changes in the membrane potential, following Winkel et al. ${ }^{66}$; depolarization of the membrane is reflected as an increase in fluorescence originating from the dye, whereas repolarization leads to a decrease in fluorescence ${ }^{67}$. Initial fluorescence levels were first recorded with the cell suspension incubated with $2 \mu \mathrm{M} \mathrm{DiSC}{ }_{3}(5)$ for about $5 \mathrm{~min}$ prior to the measurement. After the addition of supernatant of either slr0688i or dCas 9 of the same volume as the cell suspension, making the concentration of $\mathrm{DiSC}_{3}(5) 1 \mu \mathrm{M}$, the fluorescence emission spectra of the cell suspension, excited at $610 \mathrm{~nm}$, were recorded from 630 to $700 \mathrm{~nm}$ time-dependently with an FP-8500 spectrofluorometer (JASCO). Changes in the fluorescence intensity at $674 \mathrm{~nm}$ were plottted to analyze changes in membrane potential across the cytoplasmic membrane of Bacillus cells.

Casamino acid and glucose dissolved in fresh BG11 were used as positive controls, and fresh BG11 was used as a negative control. 
Supernatants were prepared by filtration from cell suspensions of slr0688i or dCas9 with a Millex-GV Syringe Filter Unit, $0.22 \mu \mathrm{m}$ (Millipore). Concentration and size fractionation were done by filtration with Amicon Ultra Centrifugal Filters (Millipore). All the supernatants and control samples were confirmed to be at the same $\mathrm{pH}$ (within approx. $\mathrm{pH} 7.6-7.8$ ) before the measurements, and when necessary, were adjusted to $\mathrm{pH} 7.6-7.8$ by addition of $\mathrm{HCl}$.

Membrane vesicles free of intracellular components were prepared from Bacillus subtilis according to the method described in Konings et al., $1973^{68}$.

Note that because the supernatant of slr0688i contained phycocyanins ${ }^{25}$, it yielded unignorable fluorescence in the tested range from 630 to $700 \mathrm{~nm}$ when excited at $610 \mathrm{~nm}$ (Supplementary Fig. 12). The fluorescence from phycocyanins disappeared when purged with oxygen, which leads to selfsensitized bleaching of phycocyanins ${ }^{69}$, or treated with heat (Supplementary Fig. 12). It was confirmed that phycocyanins did not interefere with changes in fluorescence from $\operatorname{DiSC}_{3}(5)$ (data not shown).

\section{References}

1. Bradley, R. W., Bombelli, P., Rowden, S. J. L. \& Howe, C. J. Biological photovoltaics: Intra- and extracellular electron transport by cyanobacteria. Biochem. Soc. Trans. 40, 1302-1307 (2012).

2. McCormick, A. J. et al. Biophotovoltaics: Oxygenic photosynthetic organisms in the world of bioelectrochemical systems. Energy Environ. Sci. 8, 1092-1109 (2015).

3. Tschörtner, J., Lai, B. \& Krömer, J. O. Biophotovoltaics: Green power generation from sunlight and water. Front. Microbiol. 10, (2019).

4. Zhu, H. et al. Development of a longevous two-species biophotovoltaics with constrained electron flow. Nat. Commun. 10, (2019).

5. Huntley, M. E. \& Redalje, D. G. CO2 mitigation and renewable oil from photosynthetic microbes: A new appraisal. Mitigation and Adaptation Strategies for Global Change vol. 12 (2007).

6. Li, Y., Horsman, M., Wu, N., Lan, C. Q. \& Dubois-Calero, N. Biofuels from microalgae. Biotechnol. Prog. 24, 815-820 (2008).

7. Dismukes, G. C., Carrieri, D., Bennette, N., Ananyev, G. M. \& Posewitz, M. C. Aquatic phototrophs: efficient alternatives to land-based crops for biofuels. doi:10.1016/j.copbio.2008.05.007.

8. Quintana, N., Kooy, F. Van Der \& Verpoorte, R. Renewable energy from Cyanobacteria: energy production optimization by metabolic pathway engineering. 471-490 (2011) doi:10.1007/s00253011-3394-0.

9. Pisciotta, J. M., Zou, Y. \& Baskakov, I. V. Light-dependent electrogenic activity of cyanobacteria. PLoS One 5, (2010).

10. Pisciotta, J. M., Zou, Y. \& Baskakov, I. V. Role of the photosynthetic electron transfer chain in electrogenic activity of cyanobacteria. Appl. Microbiol. Biotechnol. 91, 377-385 (2011). 
11. Bombelli, P. et al. Quantitative analysis of the factors limiting solar power transduction by Synechocystis sp. PCC 6803 in biological photovoltaic devices. Energy Environ. Sci. 4, 4690-4698 (2011).

12. Bradley, R. W., Bombelli, P., Lea-Smith, D. J. \& Howe, C. J. Terminal oxidase mutants of the cyanobacterium Synechocystis sp. PCC 6803 show increased electrogenic activity in biological photo-voltaic systems. Phys. Chem. Chem. Phys. 15, 13611-13618 (2013).

13. Cereda, A. et al. A bioelectrochemical approach to characterize extracellular electron transfer by synechocystis sp. PCC6803. PLoS One 9, 1-8 (2014).

14. Zhang, J. Z. et al. Photoelectrochemistry of Photosystem II in Vitro vs in Vivo. J. Am. Chem. Soc. 140, 6-9 (2018).

15. Saper, G. et al. Live cyanobacteria produce photocurrent and hydrogen using both the respiratory and photosynthetic systems. Nat. Commun. 9, 1-9 (2018).

16. Gorby, Y. A. et al. Electrically conductive bacterial nanowires produced by Shewanella oneidensis strain MR-1 and other microorganisms. Proc. Natl. Acad. Sci. U. S. A. 103, 11358-11363 (2006).

17. Shlosberg, Y. \& Levin, G. iScience. (2021) doi:10.1016/j.isci.2020.101892.

18. Thirumurthy, M. A. et al. Type IV Pili-Independent Photocurrent Production by the Cyanobacterium Synechocystis sp. 11, 1-11 (2020).

19. White, G. F. et al. Mechanisms of bacterial extracellular electron exchange. in Advances in microbial physiology vol. 68 87-138 (Elsevier, 2016).

20. Kowata, H., Tochigi, S., Takahashi, H. \& Kojima, S. Outer membrane permeability of cyanobacterium Synechocystis sp. strain PCC 6803: Studies of passive diffusion of small organic nutrients reveal the absence of classical porins and intrinsically low permeability. J. Bacteriol. 199, 1-11 (2017).

21. Hoiczyk, E. \& Hansel, A. Cyanobacterial cell walls: News from an unusual prokaryotic envelope. J. Bacteriol. 182, 1191-1199 (2000).

22. Gonçalves, C. F., Pacheco, C. C., Tamagnini, P. \& Oliveira, P. Identification of inner membrane translocase components of TolC-mediated secretion in the cyanobacterium Synechocystis sp. PCC 6803. Environ. Microbiol. 20, 2354-2369 (2018).

23. Stebegg, R., Schmetterer, G. \& Rompel, A. Transport of organic substances through the cytoplasmic membrane of cyanobacteria. Phytochemistry 157, 206-218 (2019).

24. Gonçalves, C. F., Lima, S., Tamagnini, P. \& Oliveira, P. Cyanobacterial secretion systems: understanding fundamental mechanisms toward technological applications. in Cyanobacteria 359381 (Elsevier, 2019).

25. Kojima, S. \& Okumura, Y. Outer membrane-deprived cyanobacteria liberate periplasmic and thylakoid luminal components that support the growth of heterotrophs. bioRxiv (2020).

26. Howitt, C. A. \& Vermaas, W. F. J. Quinol and cytochrome oxidases in the cyanobacterium Synechocystis sp. PCC 6803. Biochemistry 37, 17944-17951 (1998). 
27. Mullineaux, C. W. Co-existence of photosynthetic and respiratory activities in cyanobacterial thylakoid membranes. Biochim. Biophys. Acta - Bioenerg. 1837, 503-511 (2014).

28. Lea-Smith, D. J. et al. Thylakoid terminal oxidases are essential for the cyanobacterium Synechocystis sp. PCC 6803 to survive rapidly changing light intensities. Plant Physiol. 162, 484495 (2013).

29. Oettmeier, W. \& Soll, H. J. Competition between plastoquinone and 3-(3,4-dichlorophenyl)-1,1dimethylurea at the acceptor side of Photosystem II. BBA - Bioenerg. 724, 287-290 (1983).

30. Kyle, J. REVIEW ARTICLE PROTEIN OF PHOTOSYSTEM I1. 41, 107-116 (1985).

31. Vermaas, W. F. J., Shen, G. \& Styling, S. Electrons generated by photosystem II are utilized by an oxidase in the absence of photosystem I in the cyanobacterium Synechocystis sp. PCC 6803. FEBS Lett. 337, 103-108 (1994).

32. Pils, D. \& Schmetterer, G. Characterization of three bioenergetically active respiratory terminal oxidases in the cyanobacterium Synechocystis sp. strain PCC 6803. FEMS Microbiol. Lett. 203, 217222 (2001).

33. Berry, S., Schneider, D., Vermaas, W. F. J. \& Rögner, M. Electron transport routes in whole cells of Synechocystis sp. Strain PCC 6803: The role of the cytochrome bd-type oxidase. Biochemistry 41, 3422-3429 (2002).

34. Ouitrakul, R. \& Izawa, S. Electron transport and photophosphorylation in chloroplasts as a function of the electron acceptor. II. Acceptor-specific inhibition by KCN. Biochim. Biophys. Acta (BBA)Bioenergetics 305, 105-118 (1973).

35. Izawa, S., Kraayenhof, R., Ruuge, E. K. \& Devault, D. The site of KCN inhibition in the photosynthetic electron transport pathway. Biochim. Biophys. Acta (BBA)-Bioenergetics 314, 328-339 (1973).

36. Katoh, S. A new copper protein from Chlorella ellipsoidea. Nature 186, 533-534 (1960).

37. Honeycutt, R. C. \& Krogmann, D. W. Inhibition of Chloroplast Reactions with. 376-380 (1972).

38. Torimura, M., Miki, A., Wadano, A., Kano, K. \& Ikeda, T. Electrochemical investigation of cyanobacteria Synechococcus sp. PCC7942-catalyzed photoreduction of exogenous quinones and photoelectrochemical oxidation of water. 496, 21-28 (2001).

39. Kimimura, M. \& Katoh, S. Studies on electron transport associated with photosystem II functional site of plastocyanin: inhibitory effects of $\mathrm{HgCl} 2$ on electron transport and plastocyanin in chloroplasts. Biochim. Biophys. Acta (BBA)-Bioenergetics 283, 279-292 (1972).

40. Bombelli, P. et al. Surface morphology and surface energy of anode materials influence power outputs in a multi-channel mediatorless bio-photovoltaic (BPV) system. Phys. Chem. Chem. Phys. 14, 12221-12229 (2012).

41. Bombelli, P., Müller, T., Herling, T. W., Howe, C. J. \& Knowles, T. P. J. A high power-density, mediatorfree, microfluidic biophotovoltaic device for cyanobacterial cells. Adv. Energy Mater. 5, 1-6 (2015).

42. Wenzel, T., Härtter, D., Bombelli, P., Howe, C. J. \& Steiner, U. Porous translucent electrodes enhance current generation from photosynthetic biofilms. Nat. Commun. 9, 1-9 (2018). 
43. Yongjin, Z., Pisciotta, J., Billmyre, R. B. \& Baskakov, I. V. Photosynthetic microbial fuel cells with positive light response. Biotechnol. Bioeng. 104, 939-946 (2009).

44. McCormick, A. J. et al. Photosynthetic biofilms in pure culture harness solar energy in a mediatorless bio-photovoltaic cell (BPV) system. Energy Environ. Sci. 4, 4699-4709 (2011).

45. Gonzalez-Aravena, A. C., Yunus, K., Zhang, L., Norling, B. \& Fisher, A. C. Tapping into cyanobacteria electron transfer for higher exoelectrogenic activity by imposing iron limited growth. RSC Adv. 8, 20263-20274 (2018).

46. Sawa, M. et al. Electricity generation from digitally printed cyanobacteria. Nat. Commun. 8, 1-9 (2017).

47. Sekar, N., Jain, R., Yan, Y. \& Ramasamy, R. P. Enhanced photo-bioelectrochemical energy conversion by genetically engineered cyanobacteria. Biotechnol. Bioeng. 113, 675-679 (2016).

48. Takahashi, S. \& Murata, N. Interruption of the Calvin cycle inhibits the repair of Photosystem II from photodamage. 1708, 352-361 (2005).

49. Katoh, S. \& Takamiya, A. The iron-protein binding in photosynthetic pyridine nucleotide reductase. Arch. Biochem. Biophys. 102, 189-200 (1963).

50. Kojima, Y., Niinomi, Y., Tsuboi, S., Hiyama, T. \& Sakurai, H. Destruction of photosystem I iron-sulfur centers of spinach andAnacystis nidulans by mercurials. Bot. Mag. Shokubutsu-gaku-zasshi 100, 243-253 (1987).

51. Mus, F., Cournac, L., Caruana, A. \& Peltier, G. Inhibitor studies on non-photochemical plastoquinone reduction and $\mathrm{H} 2$ photoproduction in Chlamydomonas reinhardtii. 1708, 322-332 (2005).

52. Patterson, C. P. A. T. \& Myers, J. Anacystis nidulans'. 104-109 (1973).

53. Spolaore, P., Joannis-Cassan, C., Duran, E. \& Isambert, A. Commercial applications of microalgae. J. Biosci. Bioeng. 101, 87-96 (2006).

54. Eriksen, N. T. Production of phycocyanin - A pigment with applications in biology, biotechnology, foods and medicine. Appl. Microbiol. Biotechnol. 80, 1-14 (2008).

55. Parmar, A., Singh, N. K., Pandey, A., Gnansounou, E. \& Madamwar, D. Cyanobacteria and microalgae: A positive prospect for biofuels. Bioresour. Technol. 102, 10163-10172 (2011).

56. Ducat, D. C., Way, J. C. \& Silver, P. A. Engineering cyanobacteria to generate high-value products. Trends Biotechnol. 29, 95-103 (2011).

57. Borowitzka, M. A. High-value products from microalgae-their development and commercialisation. J. Appl. Phycol. 25, 743-756 (2013).

58. Angermayr, S. A., Gorchs Rovira, A. \& Hellingwerf, K. J. Metabolic engineering of cyanobacteria for the synthesis of commodity products. Trends Biotechnol. 33, 352-361 (2015).

59. Zhou, J., Zhu, T., Cai, Z. \& Li, Y. From cyanochemicals to cyanofactories: A review and perspective. Microb. Cell Fact. 15, 1-9 (2016).

60. Lin, P. C., Saha, R., Zhang, F. \& Pakrasi, H. B. Metabolic engineering of the pentose phosphate pathway for enhanced limonene production in the cyanobacterium Synechocysti s sp. PCC. Sci. Rep. 
7, 1-10 (2017).

61. Ogawa, T. \& Kaplan, A. The Stoichiometry between CO 2 and H + Fluxes Involved in the Transport of Inorganic Carbon in Cyanobacteria. Plant Physiol. 83, 888-891 (1987).

62. Shiraiwa, Y., Goyal, A. \& Tolbert, N. E. Alkalization of the medium by unicellular green algae during uptake dissolved inorganic carbon. Plant Cell Physiol. 34, 649-657 (1993).

63. Kamennaya, N. A., Ajo-Franklin, C. M., Northen, T. \& Jansson, C. Cyanobacteria as biocatalysts for carbonate mineralization. Minerals 2, 338-364 (2012).

64. Shaku, K., Shimakawa, G., Hashiguchi, M. \& Miyake, C. Reduction-induced suppression of electron flow (RISE) in the photosynthetic electron transport system of Synechococcus elongatus PCC 7942. Plant Cell Physiol. 57, 1443-1453 (2016).

65. Shimakawa, G., Shaku, K. \& Miyake, C. Reduction-induced suppression of electron flow (RISE) is relieved by non-ATP-consuming electron flow in Synechococcus elongatus PCC 7942. Front. Microbiol. 9, 1-11 (2018).

66. te Winkel, J. D., Gray, D. A., Seistrup, K. H., Hamoen, L. W. \& Strahl, H. Analysis of antimicrobialtriggered membrane depolarization using voltage sensitive dyes. Front. Cell Dev. Biol. 4, 1-10 (2016).

67. Sims, P. J., Waggoner, A. S., Wang, C. H. \& Hoffman, J. F. Mechanism by which cyanine dyes measure membrane potential in red blood cells and phosphatidylcholine vesicles. Biochemistry 13,33153330 (1974).

68. Konings, W. N., Bisschop, A., Veenhuis, M. \& Vermeulen, C. A. New procedure for the isolation of membrane vesicles of Bacillus subtilis and an electron microscopy study of their ultrastructure. $J$. Bacteriol. 116, 1456-1465 (1973).

69. He, J. A., Hu, Y. Z. \& Jiang, L. J. Photodynamic action of phycobiliproteins: In situ generation of reactive oxygen species. Biochim. Biophys. Acta - Bioenerg. 1320, 165-174 (1997).

\section{Declarations}

\section{Acknowledgements}

We thank Robbie Lewis, MSc, from Edanz Group (https://en-author-services.edanz.com/ac) for editing a draft of this manuscript.

\section{Author Contributions}

S.Ku., S.Ko. and S.N. conceived the idea. S.Ku., S.Ko., G.S., C.M., K.T. and S.N. designed the experiments. S.Ku. performed the experiments. S.Ku., S.Ko., K.K., G.S., C.M., K.T., Y.O. and S.N. analyzed the data. S.Ku., S.Ko, G.S, C.M., K.T and S.N wrote the paper. S.Ko. and S.N. supervised the entire research. 
Competing Interests statement

The authors declare no competing interests.

\section{Figures}
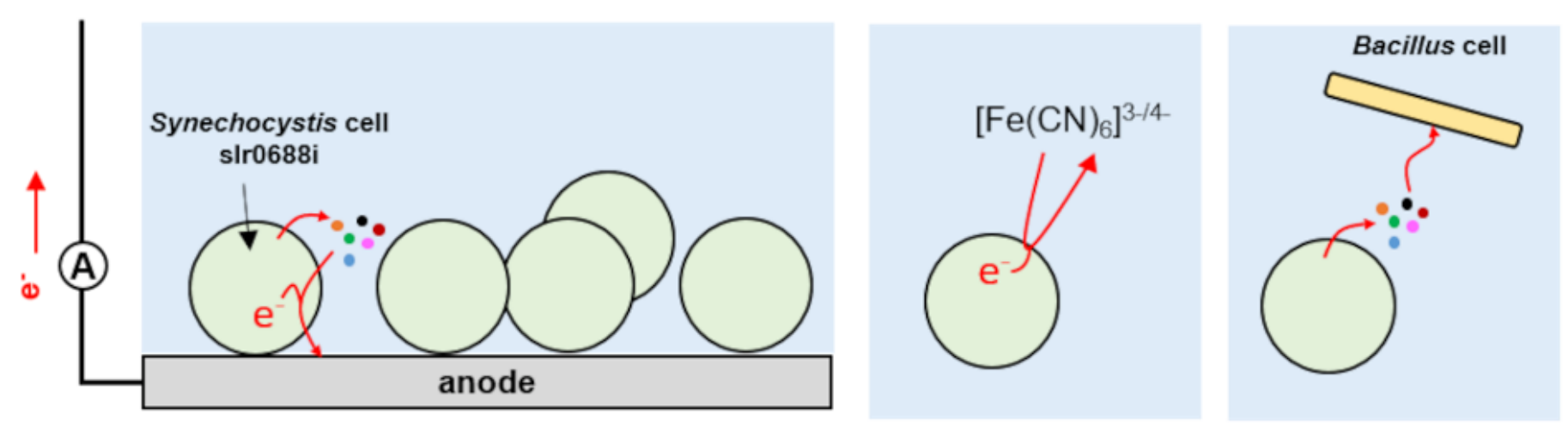

\section{Figure 1}

Schematic summary of EET from outer membrane-deprived Synechocystis cells, slr0688i. From slr0688i, reducing equivalents could be transferred to an exterior electrode via secreted compounds (mediated EET) or to an artificial electron acceptor, ferricyanide (ferricyanide-mediated EET). In addition, the extracellularly-derived reducing equivalents could serve as respiratory substrates for other bacteria (here, Bacillus cereus) i.e. electron donors in BPV systems. 
(a)

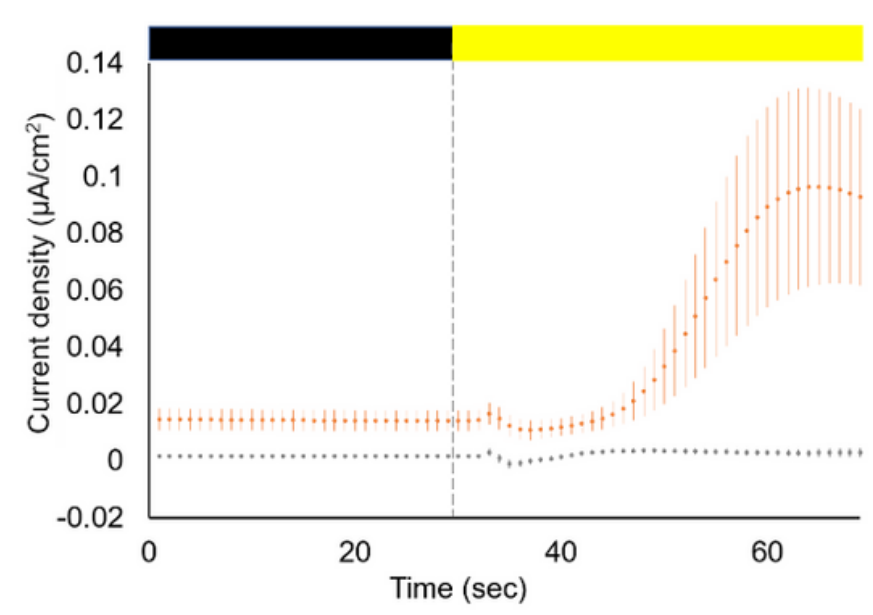

(c)

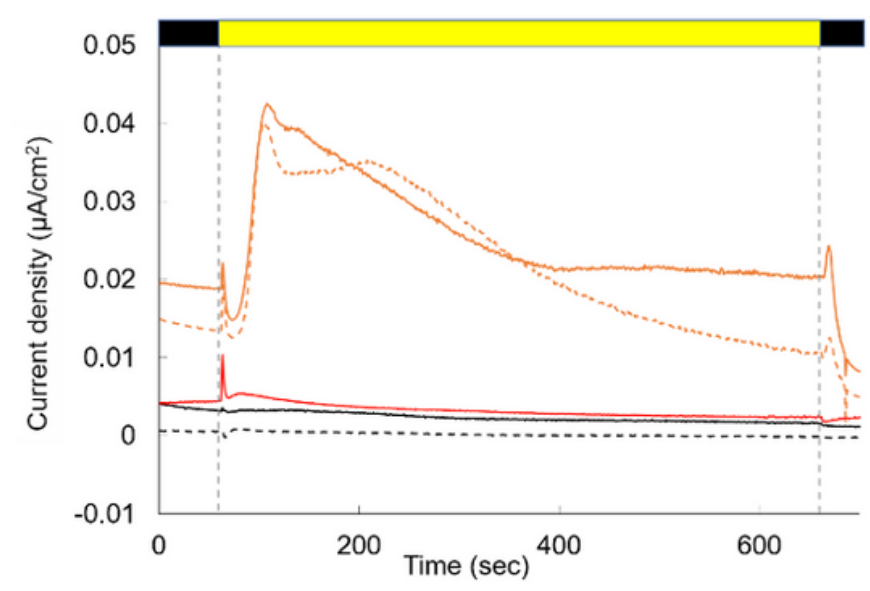

(b)

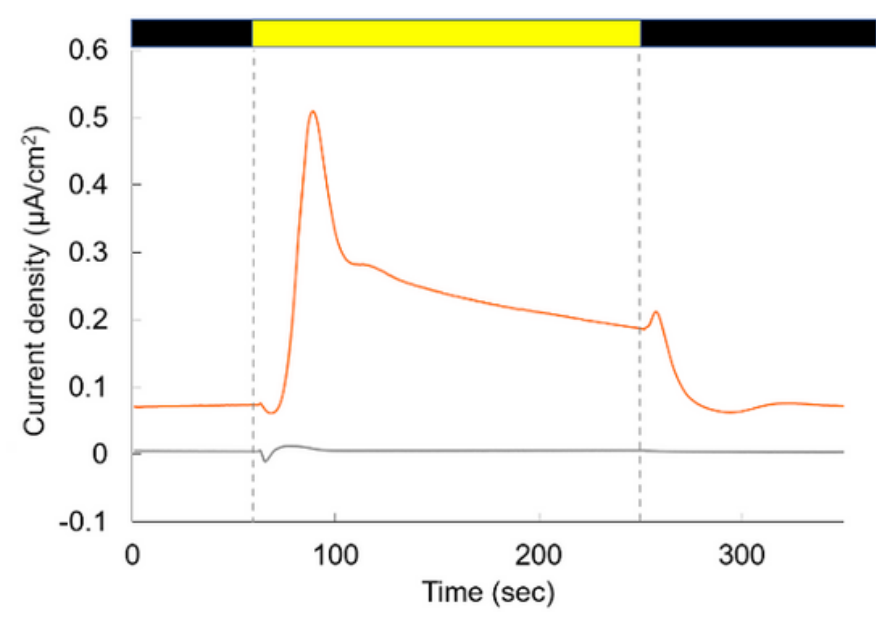

\section{Figure 2}

Photocurrent generation from Synechocystis cells. (a) Slr0688i (OD730 $=1.5$; orange points) and dCas9 $(\mathrm{OD} 730=1.5$; black points) were injected by gravity on plane ITO electrodes, and $+0.25 \mathrm{~V} \mathrm{vs} \mathrm{Ag} / \mathrm{AgCl}$ was applied to get chronoamperograms. Average values of 28 and 18 biological replicates of slr0688i and dCas9, respectively, \pm SE are shown. (b) Representative chronoamperograms of slr0688i (OD730=1.4; orange line) and dCas9 (OD730=2.0; black line) are shown. (c) The supernatant of slr0688i was substituted either with that of dCas9 (orange dotted line) or with fresh BG11 medium (red solid line). Also shown as controls are slr0688i and dCas9 suspended in their respective supernatants (orange and black solid lines, respectively), and dCas9 in slr0688i supernatant (black dotted line). All the cell suspensions were adjusted to $\mathrm{OD} 730=1.5$, and $+0.25 \mathrm{~V}$ vs $\mathrm{Ag} / \mathrm{AgCl}$ was applied. The black and yellow rectangles indicate dark and light $(100 \mu \mathrm{mol}$ photons $\mathrm{m}-2 \mathrm{~s}-1)$ conditions, respectively. 
(a)

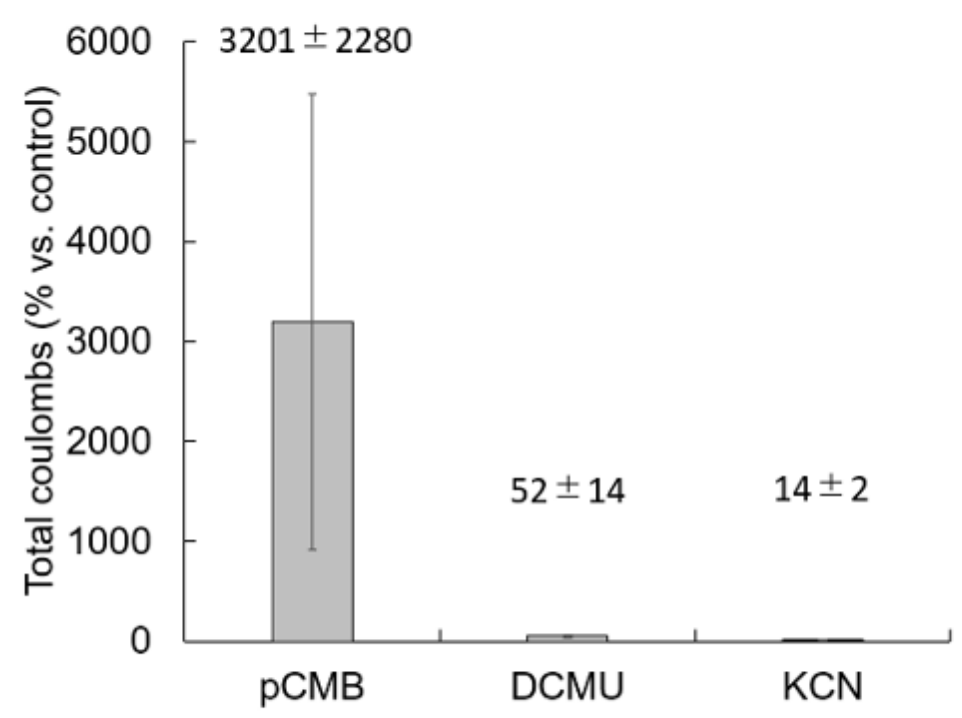

(b)

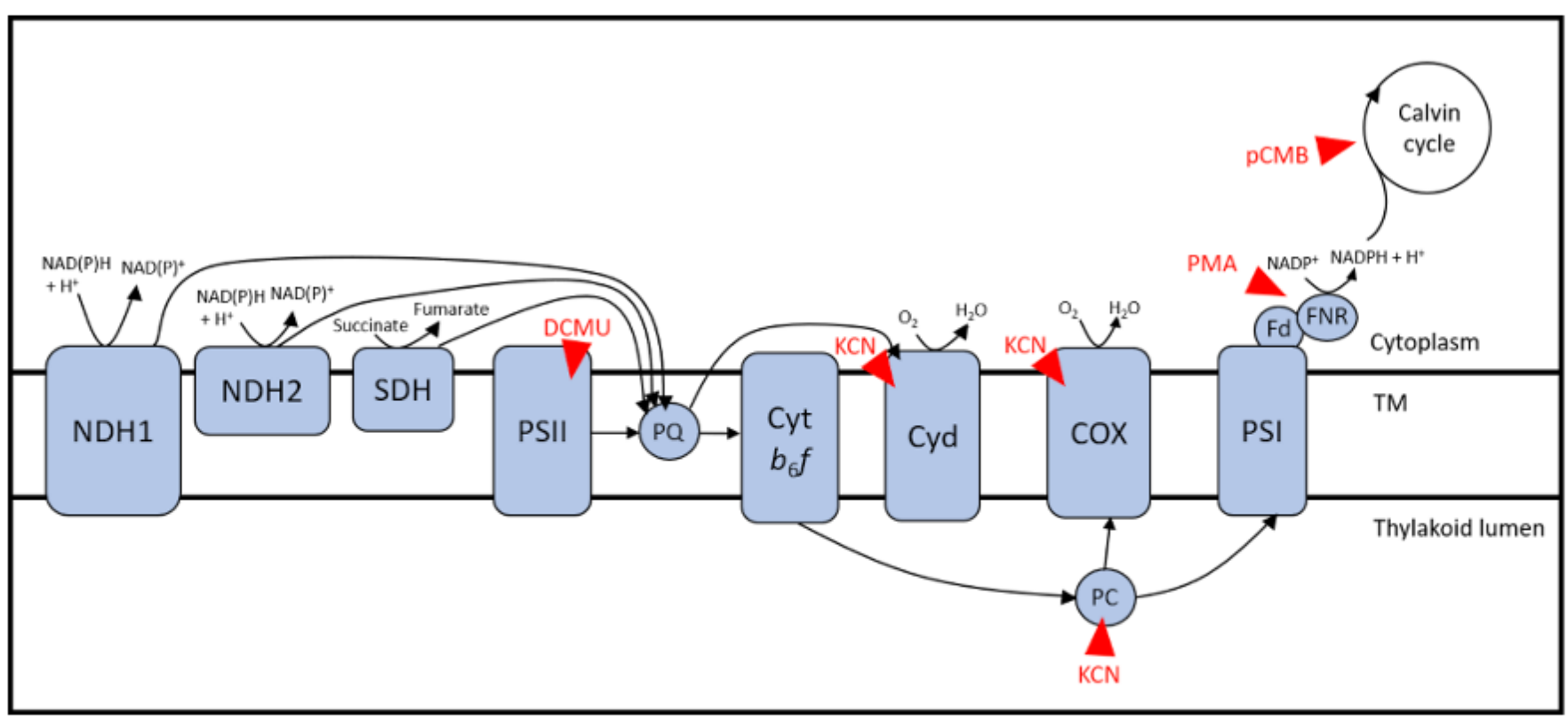

Figure 3

Effects of photosynthesis inhibitors on current generation from slr0688i. (a) Total coulombs produced at $+0.25 \mathrm{~V}$ vs. $\mathrm{Ag} / \mathrm{AgCl}$ during a 10 -min illumination of slr0688i $(\mathrm{OD730}=1.5)$ were calculated by integrating the current over time, and are expressed as percentage relative to those of controls (as to cells treated with $\mathrm{pCMB}$ and DCMU (dissolved in DMSO), cells incubated with the same amount of DMSO were taken as controls; as to cells treated with KCN (dissolved in water), cells without any addition were taken as 
controls). Average values of three to four biological replicates \pm SD are presented, which were calculated based on the data shown in Supplementary Fig. 4. (b) Target sites of the inhibitors are shown. TM, thylakoid membranes; $\mathrm{NDH}, \mathrm{NAD}(\mathrm{P}) \mathrm{H}$ dehydrogenase; SDH, succinate dehydrogenase; Cyd, cytochrome bd-quinol oxidase complex; COX, aa3-type cytochrome c oxidase.

(a)
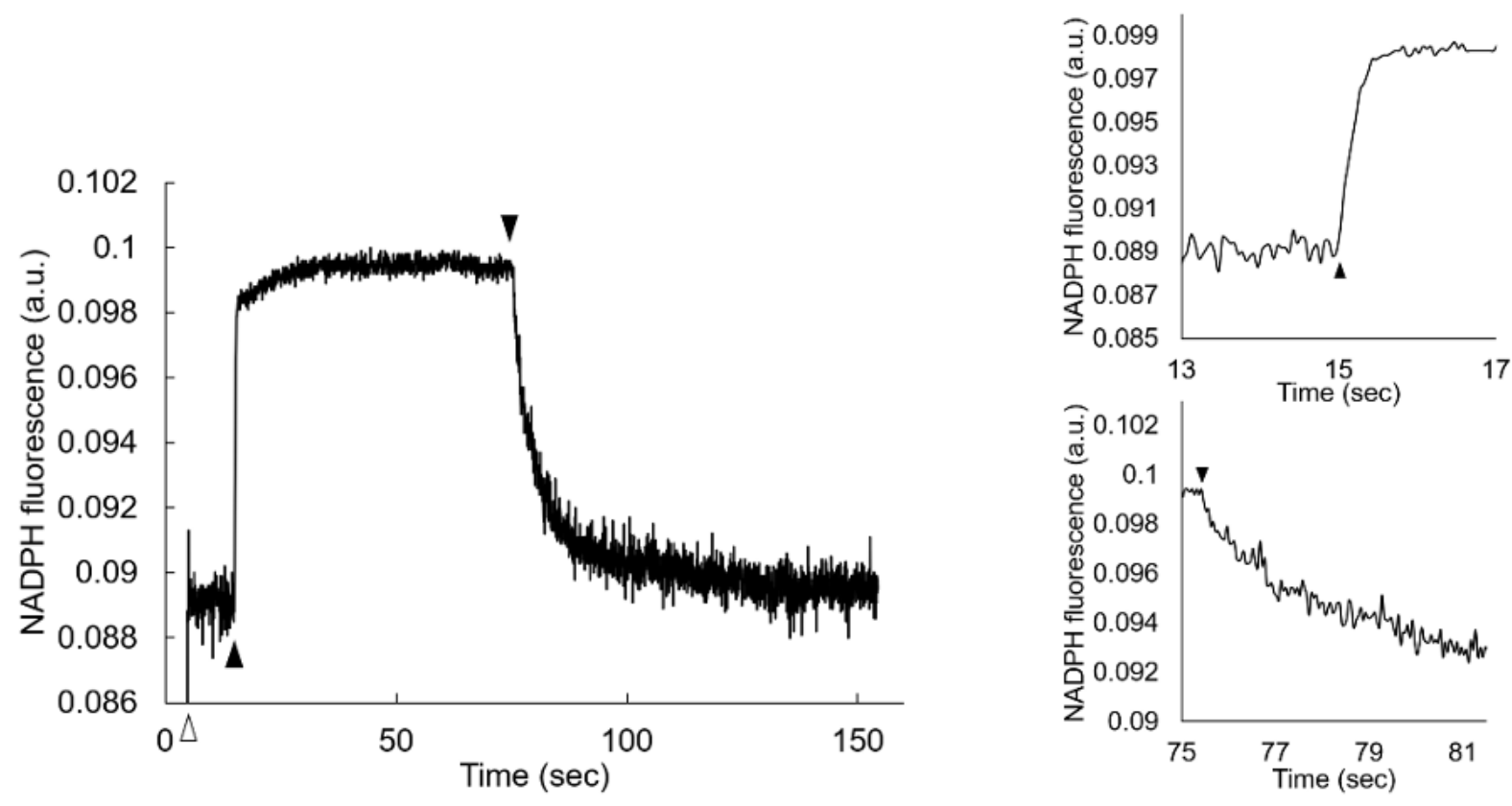

(b)
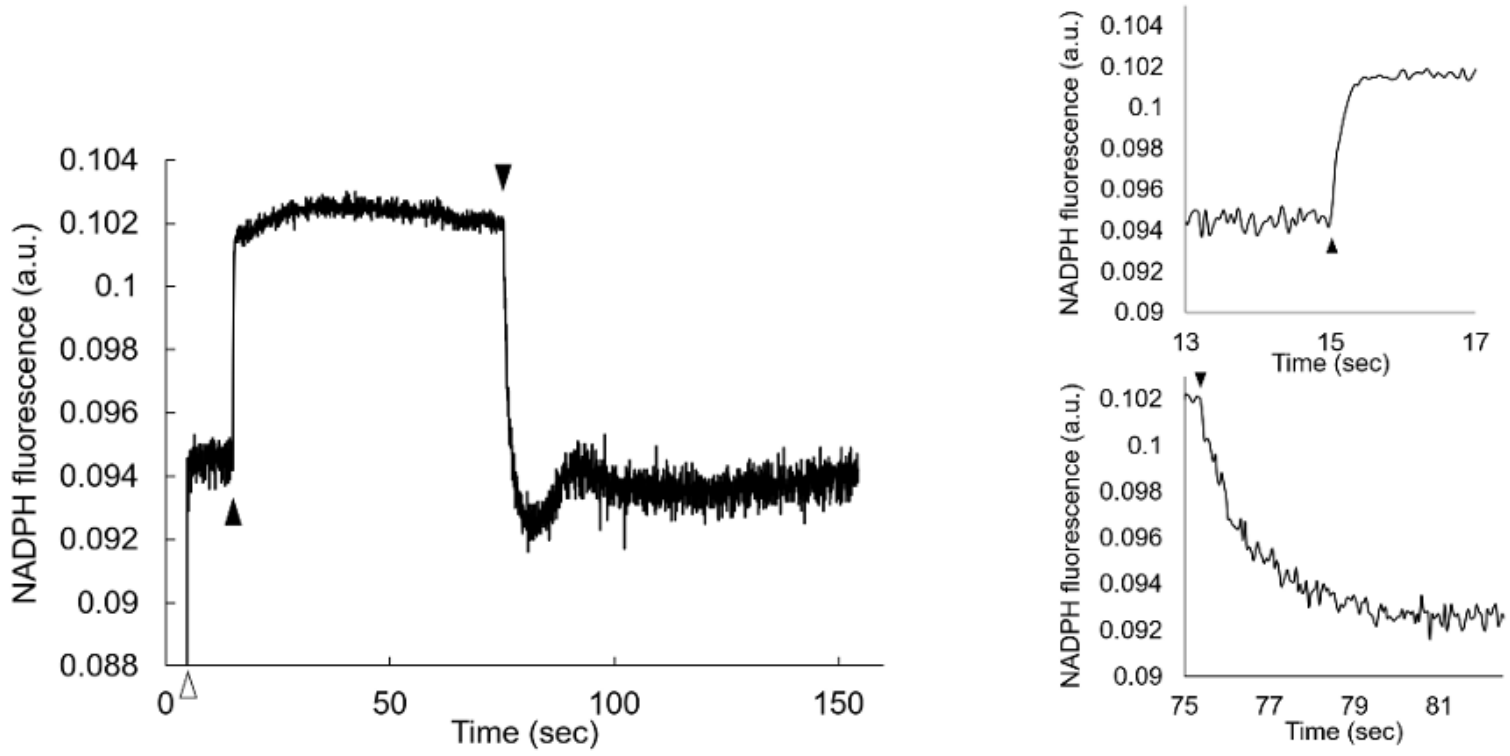

Figure 4 
The effect of pCMB on changes in NADPH fluorescence. NADPH generation upon illumination was monitored with slr0688i cells incubated with (a) pCMB or (b) its solvent DMSO for at least $1.5 \mathrm{~h}$ in the dark. The onset of the measuring light illumination is indicated by white upward triangles; the beginning and the end of the actinic light illumination are indicated by upward and downward black arrows, respectively. The traces at the beginning and at the end of the actinic light Illumination are enlarged and shown on the right.

(a)

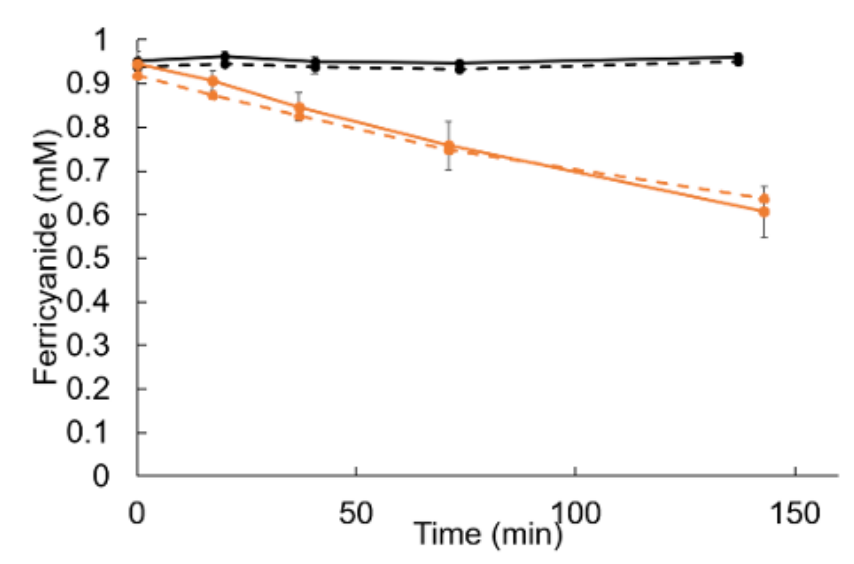

(c)

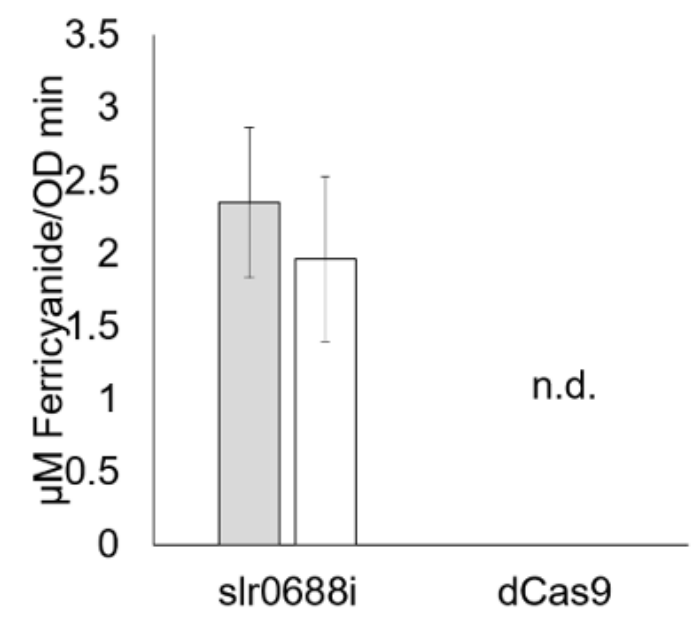

(b)

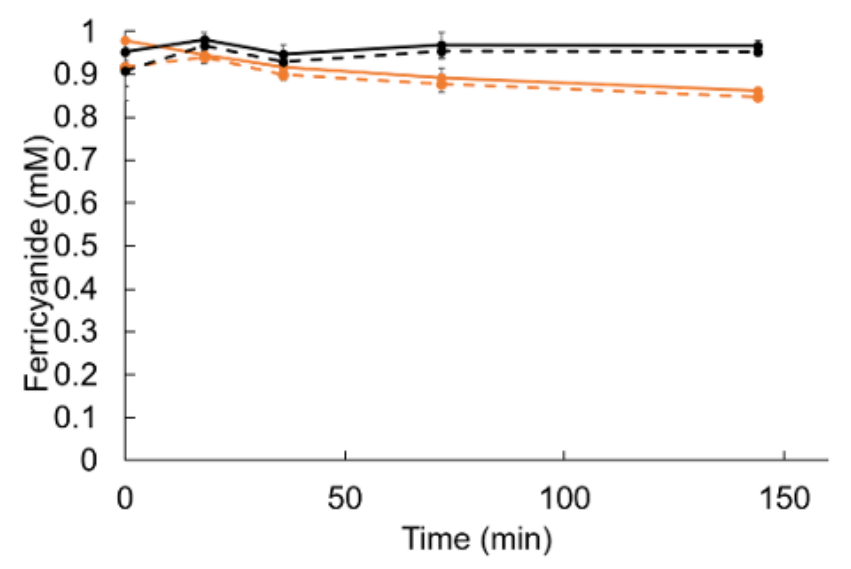

(d)

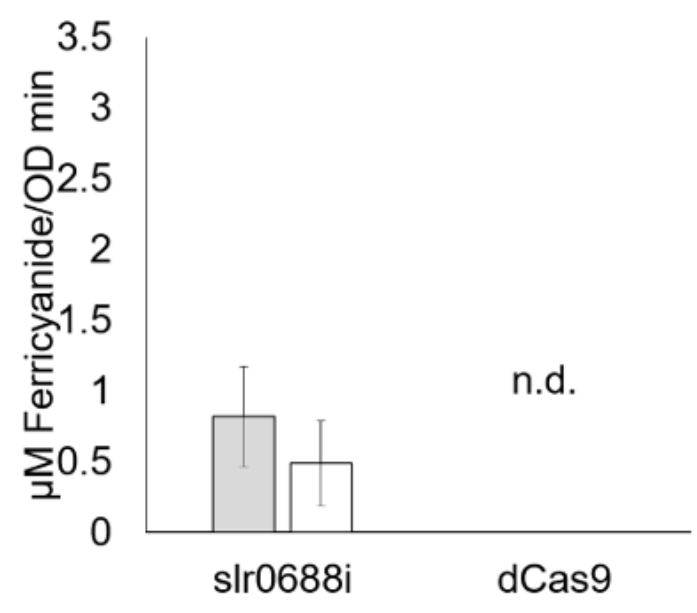

\section{Figure 5}

The rate of ferricyanide reduction by Synechocystis cells. Time-dependent reduction of ferricyanide (a) under illumination and (b) in the dark by slr0688i and dCas 9 are shown in orange and black solid lines, respectively; dotted lines indicate the data obtained when their respective supernatants were substituted with fresh BG11. Rates of ferricyanide reduction (c) under illumination and (d) in the dark by slr0688i and 
dCas9 suspended in their respective supernatants (gray bars) or fresh BG11 (white bars) were then calculated. Average values of four to five biological replicates \pm SD are shown.

(a)

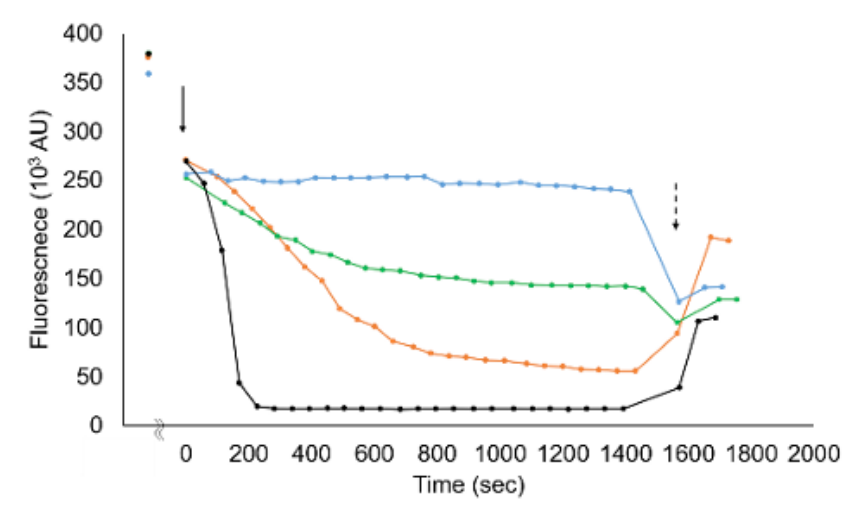

(b)

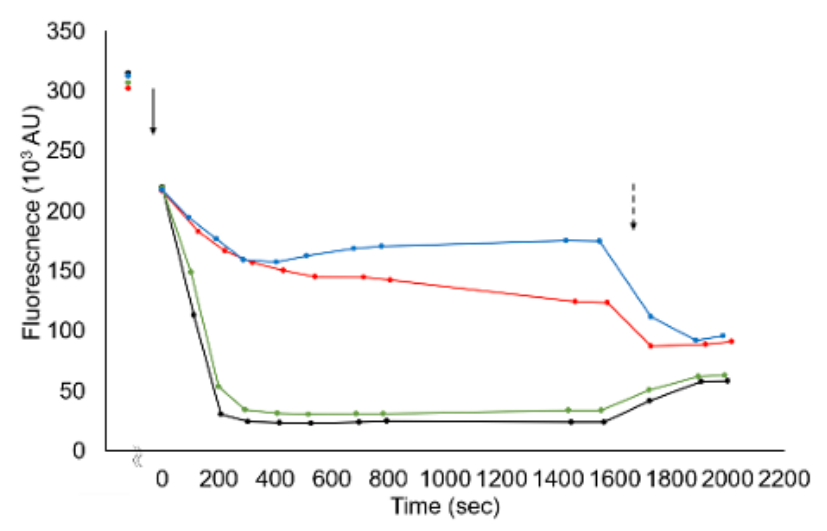

\section{Figure 6}

Generation of membrane potential of Bacillus cells by supernatant of slr0688i. Changes in membrane potential of Bacillus cells were monitored (for detail, see Materials and Methods) following addition of each sample at the time indicated by bold arrows ( $t=0 \mathrm{sec}$ ): (a) $5 \times$ concentrated supernatants with $\mathrm{MW}>$ 3,000 of slr0688i (orange) and dCas9 (green), fresh BG11 (blue), and 0.01\% (w/v) casamino acid in BG11 (black), (b) a $0.5 \times$ concentration of slr0688i supernatant (red), $100 \mu \mathrm{M}$ (black), $20 \mu \mathrm{M}$ (green), $4 \mu \mathrm{M}$ (blue) glucose in BG11. At the time indicated by dotted arrows, uncouplers were added to dissipate the membrane potential: (a) $5 \mu \mathrm{M}$ gramicidin, (b) $4 \mu \mathrm{M}$ valinomycin.

\section{Supplementary Files}

This is a list of supplementary files associated with this preprint. Click to download.

- supplementaryfigureskusamaetal.docx

- nrreportingsummary.pdf 